Cómo citar este artículo en MLA: Jaramillo Vélez, Felipe y Luis Fernando Garcés Giraldo. "De la pluralidad a la individualidad. La deconstrucción del concepto de comunidad”. Escritos 28.60 (2020): 68-78.

doi: http://dx.doi.org/10.18566/escr.v28n60.a07

Fecha de recepción: 04.10.2019

Fecha de aceptación: 09.06.2020

\title{
De la pluralidad a la individualidad. La deconstrucción del concepto de comunidad
}

\author{
From Plurality to Individuality. \\ Deconstruction of the Concept of Community
}

\author{
Felipe Jaramillo Vélez ${ }^{1}$ \\ Luis Fernando Garcés Giraldo ${ }^{2}$
}

\begin{abstract}
RESUMEN
Decidido a luchar en solitario, desguarnecido de la seguridad que le puede brindar la comunidad, el hombre actual se ha propuesto ostentar abiertamente su individualidad. Con este propósito, consciente o inconscientemente, se ha dado a la tarea de diezmar las instituciones: casa, escuela, Iglesia, etc., rompe con las cadenas impuestas por las normas, las leyes y los acuerdos realizados entre comunes y que, en últimas, considera que le oprimen y limitan su desarrollo personal. El presente texto propone una reflexión filosófica en torno al concepto de comunidad y la necesidad de su reconfiguración como amalgama social, esto como respuesta a los posibles riesgos ante el advenimiento de un nuevo individuo que, habiéndose liberado de los límites visibles que se le han impuesto, adopta su mismidad como única verdad, lo cual deriva en su desconocimiento de la otredad y la pluralidad, sumergiéndolo en el individualismo como única forma posible de ser.
\end{abstract}

Palabras clave: Comunidad; Individualidad; Instituciones; Otredad; Pluralidad.

1 Magíster en Comunicación y Educación por la Universidad Autónoma de Barcelona, España. Doctorando en Filosofía, Universidad Pontificia Bolivariana, Colombia. Vicerrector de Extensión, Universidad de Medellín, Colombia. Correo electrónico: fejaramillo@udem.edu.co

2 Posdoctor en Derecho por la Universidad Nacional de Colombia. Doctor y Posdoctor en Filosofía por la Universidad Pontificia Bolivariana, Colombia. Docente de la Dirección de Humanidades, Corporación Universitaria Remington. Investigador Senior Minciencias. Correo electrónico: luis.garces@americana.edu.co 


\begin{abstract}
Determined to fight alone, stripped from the security that could be offered by community, human beings of our times have openly embraced their individuality. With such a purpose, consciously or unconsciously, they have decided to decimate the institutions (such as home, school, Church, among others) and to break with the burden imposed by rules, laws and agreements, which they consider are oppressive and limit their personal development. Thus, the article offers a philosophical review of the concept of community and examines the necessity of its reconfiguration as social linking force. This arises as an answer to possible risks associated with the coming of a new individual that adopts her selfhood as the only truth, which leads to not acknowledging otherness and plurality, and to individualism as the only possible way of being.
\end{abstract}

Keywords: Community; Individuality; Institutions; Otherness; Plurality.

\title{
Introducción
}

J acques Derrida retoma el término deconstrucción que Martin Heidegger empleó - “destruktion”- en su libro Ser y tiempo (Heidegger, 2014, p. 33). La destrucción no tiene el sentido negativo de lo que supone sacudirse de la tradición ontológica. Debe, a la inversa, acotarla dentro de sus posibilidades positivas, decir, siempre dentro de sus límites, que están dados de manera fáctica a través de la forma en la que se formula la pregunta en todos los casos y la posible limitación del campo de investigación, impuesta de antemano. Cuando Derrida alude a la "racionalidad" en su obra De la gramatología, expresa que: "-tal vez sería necesario abandonar esta palabra, por la razón que aparecerá al final de esta frase- que dirige la escritura así ampliada y radicalizada, ya no surge de un logos e inaugura la destrucción, no la demolición sino la des-sedimentación, la des-construcción de todas las significaciones que tienen su fuente en este logos. En particular la significación de verdad” (Derrida, 1971, pp. 16-17). En el presente texto se adopta el término de igual manera, es decir, no se limita a "tirar el muro al piso", sino que pretende dar algunas indicaciones sobre cómo hacerlo, para qué hacerlo y qué posibilidades de posterior edificación existen.

La comunidad como célula que agrupa a hombres y mujeres con distintas identidades no puede entenderse como algo natural. La comunidad es una creación del hombre porque lo natural estaría dado por un desarrollo individual del ser humano como ser independiente que construye su devenir a partir de la toma de decisiones propias que lo determinan. El principio moderno de autonomía plantea que nadie debería incidir en el sujeto a lo largo de su vida (Schneewind, 2009), sin embargo, como medida de protección y para garantizar su coexistencia pacífica, los seres humanos han creado formas de asociación que limitan su libertad, pero que, a la postre, garantizan su supervivencia.

En coherencia con lo anterior y tomando en cuenta la necesidad de reflexionar acerca de lo que ha sido, es y podrá ser la comunidad, vale la pena señalar con Esposito que la época actual "anuda el fracaso de todos los comunismos a la miseria de los nuevos individualismos” (Esposito 2003, p. 21). Desde esta postura, la comunidad no es una unión de personas que se complementan entre sí, sino una agrupación de individuos congregados por las instituciones de las que son deudores. Este será el tema del primer apartado.

En la segunda parte se plantearán algunas causas de que la comunidad y su soporte, la institucionalidad, pierdan valor en los días que corren, reflexión sin la que el hombre podría llegar a un punto de no retorno, en el que el ser humano, tal como se lo conoce hasta hoy llegue a otras formas de existencia no naturales como es el advenimiento de un hombre tecnológico sin emociones, pasiones o sentimientos. 
En la tercera parte y antes de las conclusiones, se presentarán algunos conceptos que, potencialmente, contribuirían a una reconfiguración de la comunidad como elemento aglutinante de las individualidades y se hará una invitación a la reflexión sobre las principales empresas del hombre en la actualidad, las mismas que podrían llevarlo a un nuevo estadio de evolución, uno en el que su rasgo único e irrepetible, su inteligencia, eventualmente, será superado por la máquina inteligente.

\section{Acerca de la comunidad y sus formas}

Los estudios acerca de la comunidad como problema han sido prolíficos en la filosofía moderna. Estos, a su vez, tienen sustentos conceptuales en las etapas anteriores de la historia del pensamiento (Acosta \& Quintana, 2010; Pérez \& Bacarlett, 2013). La reflexión en torno a la comunidad como elemento problematizador es recurrente y la advertencia sobre un cambio radical en la interrelación humana se ha hecho latente desde distintas corrientes, pero con lugares comunes en sus acepciones tienen implícitas algunas quejas de las que es posible deducir que la forma de agrupación del hombre en el pasado no era buena y que la presente no es mejor. Esposito refrenda dicha posición cuando asevera que "[...] anudado al fracaso de todos los comunismos está la miseria emanada de los nuevos individualismos" (Esposito 2003, p. 21). En esta misma dirección, Byung-Chul Han expresa que "la sociedad disciplinar [anterior] es negativa y produce locos y criminales, y que la sociedad del rendimiento [actual] es positiva, pero genera seres humanos fracasados y marcados por la depresión" (2017, p. 26). A su vez, Sloterdijk hace un símil mitológico entre las fuerzas dionisiacas y apolíneas y el antagonismo existente entre naturaleza salvaje y civilización como constructo humano (Sloterdijk, 2018).

Huérfanos de instituciones, los hombres erráticos hacen lo que pueden para sobrellevar la vida; unidos por convicción o por obligación, se han mantenido en comunidad, bien por un asunto de supervivencia al buscar protección constante - dado que en comunidad son fuertes pero en soledad son vulnerables - , "Tal identidad con la naturaleza, clan, religión otorga seguridad al individuo... Puede sufrir por el hambre o la represión de satisfacciones, pero no por el peor de todos los dolores: la soledad completa y la duda" (Fromm, 1989, p. 61).

Aunque en nuestros días la comunidad pareciera estar dispuesta a seguir unida por la institucionalidad, esa que, como dice Lipovetsky, "se reproduce y desarrolla, pero por inercia, en el vacío, sin adherencia ni sentido" (Lipovetsky, 2000, p. 36). A pesar de esto, añade Lipovetsky, el sistema funciona. Sin embargo, la verdad sea dicha, las posibilidades de que esta siga unida se hacen cada vez más remotas, pues los elementos aglutinantes de la comunidad y que la llevaban a criterios más o menos unificados sobre el bien común y la forma de alcanzarlo se han diluido y ya no tienen sentido o, al menos, no para el joven de las nuevas generaciones que parece no estar interesado en hacer del otro parte de sí mismo.

Con el fin de desarrollar estas cuestiones se hace necesario establecer algunos puntos de identidad a modo de conceptos clave que requieren de una "definición" y un límite, pues ante la diversidad de interpretaciones que ofrece la posmodernidad filosófica que termina redefiniéndolo todo, negando lo que ya se ha establecido en la memoria colectiva con el propósito de la libre interpretación de cada uno y el 'triunfo del individualismo'. Este fenómeno es evidente en relación con el concepto fundamental de "verdad", ya que las definiciones clásicas de correspondencia con la realidad o consenso comunitario han cedido frente a las corrientes de pensamiento que niegan su existencia o redefinen el concepto de 
verdad y afirman que esta es relativa o individual, es decir, desvinculan el concepto de la objetividad defendida por el realismo metafísico. Con ello, se desconoce la construcción colectiva de identidad, se anula la memoria y se regresa a un estado natural individualista en el que todo es susceptible de distorsionarse y de ajustarse no ya a la realidad, no ya a la razón, sino a las emociones, como bien ha aclarado MacIntyre (2017).

De acuerdo con la teoría de Esposito (2003) — quizás la más transgresora de las que aquí se tratan— no es correcto afirmar lo común entre los hombres es aquello que los une, lo que los congrega alrededor de una misma expectativa y los ubica en la búsqueda conjunta de una misma meta (Quintana, 2016), sino que lo que une a los hombres en una communitas es todo lo contrario, "no [es] una 'propiedad' sino justamente un 'deber o una deuda', un conjunto de personas unidas no por un 'más', sino por un 'menos"' (Esposito, 2003, 29).

Sobre el concepto de comunidad de Esposito se puede inferir que la deuda de la que habla no se salda con dinero o bienes materiales, sino que, más bien, se configura como una deuda etérea atravesada por sentimientos que se transmutan en valores como la gratitud y la fidelidad perennes y de los que no le es posible liberarse en tanto no existe ningún acto que supere el acto "liberador" que se adeuda. A manera de ejemplo, es pertinente recordar que, para los cristianos, pagar la deuda que tienen con el Dios salvador excede sus capacidades, ese que bajó a la Tierra para liberar al hombre de la opresión del pecado y que se encuentra por doquier crucificado o postrado sangrante y con una corona que lo lacera, recordatorio permanente de la deuda que el hombre tiene con Él, la misma que deberá ser transmitida de generación en generación porque es eterna y recae sobre todos los hombres, creyentes o no, pero, particularmente, sobre aquellos que se consideran cristianos.

Cabría, entonces, formular algunas preguntas en torno a las causas de la disolución de la comunidad humana y del olvido o rechazo a la idea de tener deudas: ¿por qué se rompió ese lazo, ese deber que unía a la comunidad y que ya, al parecer, no representa nada? ¿Por qué el hombre actual se exime sin vergüenza alguna de tributar a esa deuda adquirida en comunidad? Y, por último, ¿ese pertenecer solo a sí mismo se convierte en la pena capital correspondiente al agravio para con la comunidad o son otras las consecuencias de su aislamiento?

La crisis de la institucionalidad y el desvanecimiento de células clave como son la familia, la Iglesia, la escuela y el Gobierno conllevan la desvalorización de la comunidad, desapareciendo el respeto mutuo entre quienes las representan y quienes son representados. Esa deuda que se tenía frente a un dirigente probo e impoluto se rompió cuando este, sin vergüenza alguna, decidió usar el poder para sí y no para actuar en bien de la comunidad. Corrompido el uso del poder se hacen insostenibles la cohesión social y el respeto por las autoridades.

Sin el discurso en el que se comentaban la cohesión social, la identidad común y la memoria institucional construida a lo largo de la historia, terminan las grandes historias soportadas desde lo simbólico, representaciones estéticas con que la comunidad se identificaba y representaban su orgullo hasta el punto de llevarlas consigo permanentemente a través de pinturas faciales y corporales e, incluso, en tatuajes indelebles tal como se ve en las comunidades celtas, en las de Borneo o en las maoríes que, a través de símbolos tribales marcan sus diferencias culturales e identifican los rangos de poder y la escala social que las caracteriza. 
Esta ausencia del discurso y de lo simbólico, ha llevado a que, paulatinamente, se desconozca el adjetivo "Communis en lo que lo común adquiere sentido por oposición a propio" (Esposito, 2003, p. 25). Con esto surge una comprensión individualista y egoísta de la propiedad privada muy característica de la mentalidad liberal que tiende a ignorar los problemas del otro y a olvidar la solidaridad, incluso, en situaciones límite en las que la vida o la integridad de personas concretas están en evidente riesgo.

\section{Acerca de la virtud del gobernante y del observante de la norma}

Sobre el pastor de ovejas y ovejas díscolas: El pastor, ese que conduce su rebaño por el camino correcto y a su vez protege la integridad de sus ovejas de los lobos y posibles depredadores, poco a poco se desdibuja y pierde el control sobre sí mismo y sobre las ovejas. Cansado de solo pastorear, posa su mirada en otros menesteres más apremiantes para él, dejando la manada a su libre albedrío, a merced de las fieras, pero también con la libertad suficiente para que entren en otros potreros, sin control, para que puedan devastar los campos a su antojo. Ahora, los pastores y las ovejas ya no son lo que eran, ahora son otra cosa, una cosa distinta que se hace necesario observar con otros ojos. ¿Con cuáles? Con unos que, a la luz de la verdad, aún no existen.

Cuando aquí se habla de comunidad -condición natural del hombre, al ser este un zoón politikón (Aristóteles, Política 1253a1)- se hace referencia a un colectivo que, si bien agrupa personas alrededor de un algo común —así sea una deuda- (Esposito, 2003), necesariamente se compone de un colectivo amorfo y heterogéneo en el que no todos sus integrantes cuentan con las mismas condiciones. Mientras unos tienen poderes superiores para legislar y castigar, otros solo obedecen el mandato impuesto. Así pues, la comunidad siempre estará atada a la existencia de rangos disímiles, castas en las que se diferencian con claridad aquellos que vigilan la norma y la cumplen de aquellos que solo tienen como alternativa observarla y acatarla como regla general de su accionar. Lo anterior no debería causar temor o repudio, todo lo contrario, debería ser objeto de una juiciosa custodia y se debería entender como una virtud común de los hombres que, antes que atentar contra ellos y su dignidad, los acerca a un mejor vivir en comunidad. Al respecto el Papa Pío XII comentaba en una de sus alocuciones:

¿No es acaso la sociedad humana —o al menos no debería serlo- semejante a una máquina bien ordenada, cuyos órganos concurren todos ellos al funcionamiento armónico del conjunto? Cada uno tiene su propia función, cada uno debe aplicarse al mejor progreso del organismo social, debe procurar [alcanzar] la perfección, según sus propias fuerzas y su propia virtud, si ama verdaderamente a su prójimo y tiende razonablemente hacia el bienestar y beneficio común (1944, p. 177).

Sin embargo, es necesario advertir que esto hace indispensable caracterizar a cada uno de los miembros de la comunidad, ya que no es justo ni viable que las exigencias para cada uno sean iguales porque su identidad, sus características físicas, psicológicas y espirituales no son las mismas, como tampoco sus capacidades, afinidades y grados de virtud o de vicio. Al respecto de estos dos últimos elementos urge, entre muchas otras, una recomposición del derecho penal para que este vuelva a operar según su razón de ser: "amparar determinados bienes de la vida de la comunidad, tales como la existencia del Estado, la vida, la salud, la libertad, la propiedad, etc. (los llamados bienes jurídicos, determinando para su lesión consecuencias jurídicas" (Welzel, 1956, p. 2). 
Así las cosas, a aquel que ostenta un poder superior se le debe exigir una virtud superior, un actuar sin tacha y una liberalidad ${ }^{3}$ que le faciliten entregar al que necesita y lo merece pues si el que más tiene llegara a recibir más, terminaría tan solo atesorando sin sentido ni utilidad alguna. A aquel que acata se le debe exigir una conciencia superior, que sea capaz de diferenciar el verdadero valor de las cosas de su valor superfluo, ya sea limitando para ello los excesos o procurando con esfuerzo y trabajo alcanzar el equilibrio según sea el caso. Se pretende así mantener el punto medio en el que el hombre tenga lo necesario para vivir bien, es decir, que sus necesidades básicas estén satisfechas y, además, tenga un poco de más para disfrutar sanamente del ocio (Ortega y Gasset, 1989).

La virtud ${ }^{4}$ resulta ser, entonces, el verdadero rasero para medir el actuar moral de los hombres. La virtud auténtica se encontraría en el estadio medio, el punto de equilibrio, lo de menos o lo de más serían niveles de no-equilibrio, como indica Aristóteles en su Ética Nicomáquea. En materia de la distribución de los bienes vale la pena señalar, en conexión con la teoría de la virtud y la dikelogía $a^{5}$ aristotélicas que, cuando no se tiene lo necesario para vivir bien, el hombre hace lo que sea para obtener lo que le falta y deja de lado el razonamiento práctico. $\mathrm{Si}$, por el contrario, lo que se tiene supera lo que se necesita para vivir bien, ocurre en muchos casos que la preservación del status de superioridad se convierte en una obsesión, opacándose también el razonamiento práctico.

La virtud obliga a un acto de reflexión superior, puesto que se hace imprescindible establecer qué tanto es lo necesario para vivir bien. De ninguna forma se puede asumir un valor igual para todos, debido a que unos necesitan más que otros. Un ejemplo sencillo pero ilustrativo de lo anterior está en el valor que, por derecho, se le debe otorgar a niños y ancianos debido a su indefensión. Los niños deben gozar de mayor cuidado para poder formar su cuerpo y su mente de forma adecuada y al anciano se le debe otorgar un puesto privilegiado en la sociedad ya que, al encontrarse disminuidas sus funciones vitales, merece que se le procure la muerte digna, sin dolor y sin pena. Asimismo, a las personas que padecen enfermedades incurables o impedimentos motrices o de razonamiento, se les debe ofrecer un cuidado especial, puesto que se les dificulta conseguir por sí mismos lo que requiere su atención en salud.

Sin embargo, es menester aclarar que no se sostiene a aquel que, con holgazanería, quiera vivir como una rémora. Lo que cada cual obtenga debe ser obligatoriamente el fruto de un trabajo justo, es decir, uno que no represente más de lo debido o menos. Está equivocado, por consiguiente, el que, guiado por ideologías, actúa viciosamente por defecto o por exceso. Ambos caen en un mismo error, en conductas inapropiadas que atentan por igual contra su buen vivir. Tres ejemplos: el de quienes diciendo defender la justicia, incurren en la barbarie surgida de la ira desmedida; el de quienes diciendo defender la propiedad, caen

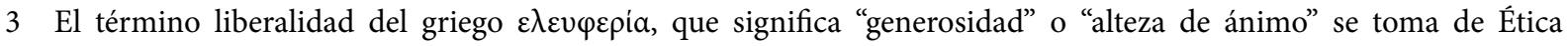
Nicomáquea: "Siendo, por tanto, la liberalidad un término medio con respecto al dar y tomar riquezas, el hombre liberal dará y gastará en lo que se debe y cuanto se debe, lo mismo en lo pequeño que en lo grande, y ello, con agrado; y tomará de donde debe y cuanto debe, pues siendo la virtud un término medio respecto de ambas cosas, hará las dos como es debido" (1120b27-32).

4 El concepto de virtud se adopta aquí a partir de los postulados de Aristóteles en Ética a Nicómaco: "Que hemos de actuar según la recta razón es un principio común y que damos por supuesto [...] la virtud es, como se ve, una potencia procuradora y preservadora de bienes, así como la potencia de hacer muchos y grandes beneficios, y de todas clases respecto de todo" (Aristóteles. Ética Nicomáquea 1103b32).

“Ciencia de la justicia” según Goldschmidt (1987). 
en la avaricia y el de los ingratos que, apelando a los errores del sistema o de sus congéneres, descuidan sus deberes para con el todo social, es decir, lo que Aristóteles denominó justicia legal:

El ingrato lo es frente a ese don obligatorio que lo constituye y hace que sea lo que es: y lo es también de manera necesaria, pues la comunidad es siempre esa morada (im)posible de la que debemos partir, aun cuando nunca dejemos de habitar en ella" (Cano 2010, 93-94).

Esto significa que, dentro de la comunidad, pueden surgir voluntades que rompan su equilibrio. La ingratitud es un acto de renuncia a las obligaciones de la comunidad, y esto, bajo ciertas condiciones, deriva en importantes injusticias e inequidades (Esposito, 2009).

La reflexión sobre lo que es necesario debería darse en lo personal y ser el resultado de un acto de libertad, pero sin que dicha libertad se convierta en argumento para ocultar la necesidad del consenso comunitario, del necesario imperio de la ley y del control que a la rama judicial del poder público le corresponde. Esto, a su vez, requiere un saneamiento del Ejecutivo y el Legislativo, de forma que quienes lo conforman se distingan por su virtud moral y su cualificación intelectual y administrativa.

Lo que se ha expuesto hasta aquí no se debe relacionar de modo alguno con formas de gobierno que se acercan a las dictaduras o a socialismos recalcitrantes. Lo que se viene planteando se acomoda más como modelo de gobierno -aunque a todas luces imperfecto- a la democracia, que peca de ingenua (Armstrong, 2009), ya que su existencia requiere de la igualdad de todos los hombres que se encuentran bajo su mandato y esgrime la libertad de elección como garantía de objetividad porque resulta innegable el hecho de que, a la hora de votar por un gobernante, la cooptación de votos es una práctica generalizada. Peor sería negar los casos de corrupción al presentar veladamente un gobierno del pueblo que, en realidad, es un gobierno demagógico ${ }^{6}$, una dictadura que comúnmente se disfraza de democracia, caso en el que el pueblo no tiene control sobre las decisiones, puesto que su opinión como mayoría, expresada en una consulta popular, suele ser desechada por quien ostenta el poder que, valiéndose de artilugios, niega la existencia de la voluntad de la mayoría y hace primar sus intereses personales y los del séquito que lo rodea. No obstante, se debe reconocer que la democracia es la única forma de gobierno en la que se expresan el pensar y sentir del pueblo que, ocasionalmente y en estado de lucidez, podría premiar con el poder a aquellos que trabajan por el bien común y condenar con la ausencia de poder los casos de mala gobernanza (Kioupkiolis 2018), esto es, auspiciar un ambiente propicio para que germinen valores de equidad y justicia, que son garantes de estabilidad y orden.

En la ausencia de élites virtuosas (Corrêa, 1993) se encuentra la primera causa de que la sociedad dejase de funcionar como unidad constitutiva para la acción de los hombres. Esta ausencia de virtud radicaría, fundamentalmente, en una negación a saldar la deuda adquirida por las clases rectoras de la sociedad, pues los obligados a crear, observar y velar por el cumplimiento de las normas solo aplican lo primero y lo tercero a su conveniencia, adosándose el poder adquirido para defender su actuar impropio y eximiéndose así de castigo y de pena, injusticia muy propia de la dictadura, de un gobierno perverso e imperfecto, no

6 Cuando se refirió a las diversas formas que presenta la democracia -que antes que haber sido superada en nuestros días, se presenta con frecuencia como una forma perversa de ejercer un gobierno muy poco "democrático-, Aristóteles declaró en La Política: “donde las leyes no son soberanas, ahí surge[n] los demagogos”, (Aristóteles. Política, 1292a27). 
de una democracia. Si se acepta este planteamiento cobra sentido eximir de culpabilidad a los miembros de la comunidad en las sociedades controladas, como indica Foucault (2002). Esta acusación también ha sido criticada por Byung-Chul Han (2017). En síntesis, la pérdida de la comunidad es responsabilidad de quienes, debiendo cuidarla, se encargaron de malograrla y de generar un estado anárquico en el que todo pacto se anula dado que su basamento carece de sentido y, en consecuencia, deja tan solo dos formas de comportamiento: la obediencia reflexiva y la desobediencia civil con los efectos nocivos que esta puede tener en algunos casos.

\section{Acerca de las bondades de acatar la norma}

De forma encadenada, un tercer punto de identidad está dado por la necesidad de la observancia a rajatabla de la norma y de la obligatoriedad del cumplimiento sin prerrogativas del castigo impuesto por su lesión como elementos ordenadores de la sociedad, teniendo cuidado en este punto de fijar tácitamente que las normas no se pueden asumir como absolutas y que, por tanto, su acogida no obedece a una regla universal. Su observancia se limita exclusivamente a su jurisdicción -una frontera que no necesariamente es física o espacial y que delimita el espacio de una comunidad determinada- y no se extiende a la totalidad de la raza humana. Es por esto por lo que su poder solo puede ejercerse sobre aquellos que voluntariamente hagan parte de la comunidad en la que la norma es vigente.

La norma, como ya se ha advertido, está dada por y para individuos, lo que lleva, necesariamente, a establecer escalas de actuación que no se enmarcan en principios de igualdad -solo en estado natural todos somos iguales- sino en principios de equidad que no tienen por qué ser vistos como parte de un acto discriminatorio o como una conducta impropia que vaya en desmedro de la identidad de las personas (Groppo, 2011).

La aceptación de estas escalas lleva al hombre a un mejor entendimiento de sí y a estar mejor consigo mismo y con los demás.

La norma es el elemento mediante el que el hombre le pone límite al comportamiento natural y por medio del que se establecen conductas y formas comportamentales específicas de actuación en comunidad, pues, aunque sean subjetivas, resultan del consenso y en un régimen democrático establecen lo que se entiende por bienestar y malestar, aun cuando no sea aceptado por todos. Lo anterior presupone dos situaciones: la primera es la renuncia voluntaria a la libertad para mejorar la calidad de vida o, al menos, para evitar morir anti-naturalmente (Hobbes, 2011, p. 102) y la segunda es la renuncia al mundo como territorio, lo que, según Sloterdijk, lleva "a limitar su espacialidad a cercados artificiales que garantizan unidades de supervivencia comunes" (2018, p. 36).

Una vez se admite lo anterior como un hecho cultural, se advierte una tercera causa de la ruptura actual del hombre con la comunidad. Se trata de la subjetivación con respecto a la valoración de lo impuesto por la norma, que se convierte en la escala de actuación que ya no se establece sobre principios absolutos, sino que se presta a las interpretaciones individuales de mínimos y máximos. Esto implica que el espíritu sobre el que se creó dicha escala se desvanezca, esto es, que ya no haya criterios claros para juzgar la gravedad de la infracción atendiendo a las circunstancias en que ocurrió, a los móviles y a las consecuencias, afirmándose así un positivismo jurídico duro que niega la existencia de la epiqueya, 
entendida como acción hermenéutica que le permite al hombre liberarse de la letra de la ley en favor de su espíritu (Massini, 2005). Las justas medidas no existen, la virtud es totalitaria, se tiene o no se tiene, para ella no hay puntos medios.

La ausencia de norma vuelve al hombre proclive a su auto-determinación. Se provoca con esto el regreso a un mundo salvaje en donde, ya sin la domesticación que presenta Sloterdijk (2001), el hombre se enfrenta nuevamente a la presión de un entorno puramente natural en que sus actuaciones son el resultado de una reacción de supervivencia en un ambiente no controlado como el que alberga a la comunidad, pierde con ello toda noción de principios rectores y se entrega básicamente a la respuesta a estímulos primarios en los que la fuerza física vuelve a imperar nuevamente como arma de protección (Corrêa, 2019).

Esto supone un retroceso que, finalmente, entrega al hombre su tan anhelada "libertad" y, a su vez, lo devuelve al mundo de las sombras, ese en donde se hace cada vez más latente el advenimiento de un punto de no retorno para la humanidad, uno en el que el hombre deje de existir.

\section{De la necedad humana (a manera de conclusión)}

Más que un tiempo sin respuestas, lo que el hombre está viviendo en la actualidad es un tiempo sin conciencia. El ascenso del hombre lo ha llevado a hacer lo impensado y no se hace referencia con ello a ir al espacio o a descifrar el código del genoma humano. De lo que se habla es de poner en riesgo a sus semejantes y al planeta mismo y sus recursos. Tanta inteligencia mezclada con tanta necedad produce nubarrones que impiden ver que lo que el hombre necesita está ahí ante sus ojos, presto para ser usado como antídoto para acabar con todos los males que aquejan a la humanidad.

El advenimiento de las individualidades sobre las pluralidades propone un acercamiento del hombre a lo que considera su "verdadera libertad", una ruptura total con la deuda adquirida con los otros, una obsolescencia del pacto social firmado tácitamente, una pérdida del miedo a las consecuencias de sus actos.

El desconocimiento de los límites deja abierta una brecha infranqueable para el hombre. Ante la imposibilidad de sostener un pacto que lo acerca a la buena vida, no adviene una inteligencia superior capaz de administrar la libertad conseguida (Groppo, 2011).

Aproximadamente desde el comienzo de la Modernidad, el hombre ha dado pasos agigantados en la línea de su involución; su movimiento, siempre descendente, ha sido constante. Primero se presentó el atentado contra lo natural, que se volcó luego contra las formas anti-naturales que hacen parte del movimiento descendente; la pérdida de la comunidad como amalgama social se hizo cada vez más notoria, máxime si se apropian -como se pretende- los postulados filosóficos postmodernos que invitan a la no-obediencia como respuesta a las inconformidades que emanan del actuar errado de gobiernos fallidos, aun cuando se trate de democracias o de dictaduras -ambas carecen de la verdadera virtud-, sin advertir que con esto lo único que se logra es abrir un tanto más la brecha y provocar situaciones irreconciliables nubladas en lo absoluto por la no-razón.

Sería fácil, entonces, recomponer el camino hacia la búsqueda de la felicidad, es decir, de la buena vida. Solo bastaría que el hombre hiciese uso del entendimiento que lo diferencia de las cosas, las plantas y 
los animales que lo rodean. Sería suficiente con reflexionar sobre cada acto para luego dar rienda suelta a la acción o limitarla por el bien común, que es, a la vez, el bien propio -otra falsa antinomia que hay que disolver-. El ceder la inteligencia de actuar a las cosas y endosarle a las máquinas esta facultad, no necesariamente representa un triunfo para el hombre, el "dar vida" de manera instrumental es una acción antinatural que, en realidad, atenta contra la vida que obedece a un poder natural superior. Cambiar el orden de las cosas trasgrede lo que se ha establecido como conveniente, resta y divide más de lo que suma y multiplica (Serrano, 2017).

El triunfo de las singularidades sobre las pluralidades representa una amenaza para el hombre, puesto que, al desaparecer el todo que es la comunidad, las partes por sí solas noi harán que el sistema funcione de manera estable, y, claro está, que aquello que funciona mal no otorga garantía alguna a quien pretende darle un uso con propósitos de un bien deseado.

\section{Referencias bibliográficas}

Acosta, María del Rosario, \& Quintana, Laura. De la estetización de la política a la comunidad desobrada. Revista de Estudios Sociales 35 (2010): 53-65.

Aristóteles. Ética Nicomáquea. Ética Eudemia. Madrid: Gredos, 1998.

Aristóteles. La Política. Madrid: Centro de Estudios Políticos y Constitucionales, 2018.

Armstrong, Aurelia. Natural and Unnatural Communities: Spinoza Beyond Hobbes. British Journal for the History of Philosophy 17.2 (2009): 279-305.

Cano, Virginia. Del don a la ingratitud: vida, comunidad e inmunidad en Roberto Esposito y Nietzsche. Contrastes: Revista Internacional de Filosofía 15.1-2 (2010): 85-103.

Corrêa de Oliveira, Plinio. Nobleza y élites tradicionales análogas en las alocuciones del Pío XIII al Patriciado y a la nobleza romana. Madrid: Fernando III, el Santo,1993.

Corrêa de Oliveira, Plinio. Tribalismo indígena, ideal comuno misionero para el siglo XXI. Bogotá: Fundación Plinio Corrêa de Oliveira, 2019.

Derrida, Jacques. De la gramatología. México: Siglo XXI, 1971.

Esposito, Roberto. Communitas. Origen y destino de la comunidad. Buenos Aires: Amorrortu, 2003.

Esposito, Roberto. Bíos. Biopolítica y filosofía. Buenos Aires: Amorrortu, 2006.

Esposito, Roberto. Immunitas. Protección y negación de la vida. Buenos Aires: Amorrortu, 2009.

Foucault, Michel. Vigilar y castigar: nacimiento de la prisión. México: Siglo XXI, 2002.

Fromm, Erich. El miedo a la libertad. Barcelona: Paidós, 1989.

Goldschmidt, Werner. Dikelogía. Ciencia de la justicia. Buenos Aires: Depalma, 1987.

Groppo, Alejandro. Tres versiones contemporáneas de la comunidad: Hacia una teoría política postfundacionalista. Revista De Filosofía Y Teoría Política 42 (2011): 49-68.

Han, Byung-Chul. La sociedad del cansancio. Barcelona: Herder, 2017.

Heidegger, Martin. Ser y Tiempo. México: Fondo de Cultura Económica, 2014.

Hobbes, Thomas. Leviatán. México: Fondo de Cultura Económica, 2011.

Kioupkiolis, Alexandros. Commoning the political, politicizing the common: Community and the political in JeanLuc Nancy, Roberto Esposito and Giorgio Agamben. Contemporary Political Theory 17.3 (2018): 283-305.

Lipovetsky, Gilles. La era del vacío. Ensayos sobre el individualismo contemporáneo. Barcelona: Anagrama, 2000.

MacIntyre, Alasdair. Ética en los conflictos de la Modernidad. Sobre el deseo, el razonamiento práctico y la narrativa. Madrid: RIALP, 2017.

Massini, Carlos Ignacio. Filosofía del derecho Tomo II. La justicia. Buenos Aires: LexisNexis, 2005.

Pérez Bernal, Ángeles Ma. \& Bacarlett Pérez, María Luisa. De la crisis de la comunidad a la comunidad de la crisis: algunas paradojas del estar en común. Areté 25.2 (2013): 307-335. 
Quintana, Laura. "Unos-con-otros y unos-de-otros": comunidad y alteridad en el pensamiento de Hannah Arendt. En: Cepeda, Margarita \& Arango Rodolfo (Comps.). Amistad y alteridad. Homenaje a Carlos B. Gutiérrez (pp. 201-212). Bogotá: Universidad de Los Andes, 2016.

Rosset, Clément. Lo real. Tratado de la idiotez. Valencia: Pre-Textos, 2004.

Schneewind, Jerome Borges. La invención de la autonomía. Una historia de la filosofía moral moderna. México: Fondo de Cultura Económica, 2009.

Serrano Ruiz-Calderón, José Miguel. Transhumanismo: La proyección de la miseria. Una lectura desde Gómez Dávila. En Abad Torres, Alfredo (Compilador). Entre fragmentos. Interpretaciones gomezdavilianas (pp. 201220). Pereira: Casa de Asterión, 2017.

Sloterdijk, Peter. Normas sobre el parque humano. Una respuesta a la Carta sobre el humanismo de Heidegger. Madrid: Ediciones Siruela, 2001.

Sloterdijk, Peter. ¿Qué paso en el siglo XX? Madrid: Siruela, 2018.

S.S Pío XII. Discorsi e radiomessagi di sua santità Pio XII Vol. V. Quinto Anno di Pontificato. Milano: Vita e Pensiero, 1944.

Welzel, Hans. Derecho Penal. Parte General. Buenos Aires: Roque Depalma, 1956. 